\section{Gastropatía hipertrófica por IgG4. Reporte del primer caso en Chile}

\author{
ZOLTÁN BERGER ${ }^{1,4}$, MARÍA IGNACIA LEA-PLAZA PUIG ${ }^{5, a}$, \\ CRISTIAN VARELA ${ }^{2}$, MARINA BECERRA ${ }^{1}$, \\ MARÍA CAPETILLO ${ }^{3}$, JUAN VARGAS ${ }^{3}$
}

\section{IgG4 related hypertrophic gastropathy. Report of one case}

IgG4 related disease is a systemic autoimmune disease, which can affect different organs. The most common digestive manifestation is autoimmune pancreatitis (AIP), followed by involvement of bile ducts and the major papilla. The stomach is only rarely involved. We report a 71-year-old diabetic woman consulting for jaundice and weight loss. Abdominal CAT scan, cholangio resonance imaging, endosonography and a serum IgG4 of five times the normal value, lead to the diagnosis of an autoimmune pancreatitis. An upper gastrointestinal endoscopy showed a diffuse thickening of gastric folds. The pathological study confirmed the presence of IgG4 positive plasma cells. The patient was successfully treated with steroids.

(Rev Med Chile 2019; 147: 119-124)

Key words: Gastritis, Hypertrophic; Immunoglobulin G4-Related Disease; Pancreatitis.

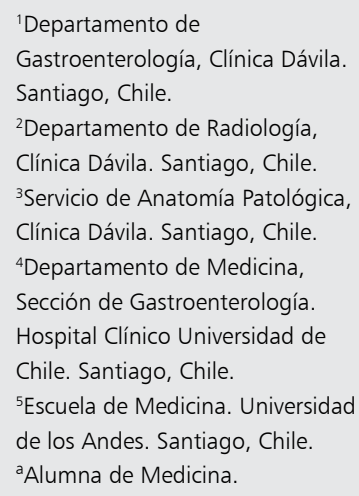

No hubo apoyo financiero.

Recibido el 22 de junio de 2018 , aceptado el 27 de diciembre de 2018.

Correspondencia a:

Zoltán Berger

Departamento de Medicina, Sección de Gastroenterología, Hospital Clínico Universidad de Chile. Santos Dumont 999, Independencia. Santiago, Chile. berger.zoltan@gmail.com

\section{L} a enfermedad relacionada a inmunoglobulina G4 (IgG4) es una patología autoinmune caracterizada por la presencia de crecimiento pseudotumoral de los órganos afectados, infiltrado linfoplasmocitario, predominantemente por células plasmáticas IgG4 positivas y un grado variable de fibrosis, generalmente en forma de remolino, acompañada frecuentemente por venulitis. En la actualidad, esta enfermedad es uno de los principales "simuladores", ya que puede comprometer casi todos los órganos ${ }^{1,2}$, representando dificultades en el diagnóstico diferencial. El diagnóstico histológico depende de la accesibilidad del órgano afectado, en algunos casos la biopsia es relativamente fácil de obtener, como las glándulas salivales (tumor de Küttner) o ganglios linfáticos (enfermedad de Castleman), pero en otros casos, como en la aortitis, es prácticamente imposible. La confirmación del diagnóstico cambia radicalmente el pronóstico de estos pacientes, ya que la mayoría responde rápidamente a los glucocorti- coides, logrando una recuperación completa sin la necesidad de intervenciones invasivas.

Aunque la manifestación digestiva más frecuente de la enfermedad sistémica relacionada a IgG4 es la pancreatitis autoinmune (PAI) tipo 1, otros órganos digestivos y extradigestivos pueden estar comprometidos, destacando la nefritis, fibrosis retroperitoneal y aortitis, entre otras ${ }^{3-6}$. En nuestra experiencia, el compromiso más frecuentemente asociado a la PAI tipo 1 es a nivel de glándulas salivales y conductos biliares ${ }^{7}$, siendo extremadamente raro el compromiso gástrico. A este nivel, se han reportado desde casos esporádicos con úlceras, lesiones polipoideas, masas submucosas y engrosamiento parietal ${ }^{8-15}$, hasta manifestaciones morfológicas y clínicas de síndrome de Ménétrier ${ }^{16}$. Otros también han descrito compromiso de la papila de Vater, demostrando papilitis con infiltración por linfoplasmocitos IgG4 positivos ${ }^{17,18}$.

Comunicamos nuestra observación sobre el 
primer caso en Chile con manifestación gástrica demostrada por enfermedad relacionada a IgG4. Nuestra paciente dio su consentimiento firmado para la publicación de su caso.

\section{Caso clínico}

Mujer de 71 años, diabética tipo 2, insulino-requiriente, hipertensa. Consultó por un cuadro de tres semanas de evolución caracterizado por ictericia de piel y mucosas, coluria, acolia y baja de peso, sin fiebre. En los exámenes de laboratorio destacaba: bilirrubina total: $13 \mathrm{mg} / \mathrm{dL}$; GGT 1.188 $\mathrm{U} / \mathrm{L}$; fosfatasas alcaninas: $497 \mathrm{U} / \mathrm{L}$, transaminasa glutámico oxalacética: $211 \mathrm{U} / \mathrm{L}$, transaminasa glutámico pirúvca: $216 \mathrm{U} / \mathrm{L}, \mathrm{CA19}-9: 57,3 \mathrm{U} / \mathrm{mL}$, glicemia $365 \mathrm{mg} / \mathrm{dL}$, albuminemia 3,1 g/dL. En la ecotomografía abdominal, la vesícula biliar se apreciaba sobredistendida con vía biliar intra y extrahepática dilatada, sin cálculos. En las imágenes de tomografía computada (TAC) de abdomen se confirmó la marcada dilatación de la vía biliar intra y extrahepática, sin evidencia de masa en la cabeza de páncreas, con múltiples adenopatías vecinas al ligamento gastrohepático, porta-hepático, adyacente al tronco celíaco y margen anterior del mesenterio. Se observaron múltiples focos de nefritis bilateral y un marcado engrosamiento de la pared gástrica y de los pliegues gástricos (Figura 1 A). La colangioresonancia mostró una larga estenosis del segmento intrapancreático del colédoco, producida por aumento de tamaño de cabeza de páncreas. Las vías biliares intra y extrahepática se apreciaron dilatadas hasta el borde del páncreas, sin observar coledocolitiasis ni un proceso expansivo. Se confirmó también el engrosamiento de la pared gástrica e hipertrofia de sus pliegues (Figura $1 \mathrm{~B})$. En la endosonografía, solo se apreciaron cambios inflamatorios en cabeza del páncreas, sin identificar una masa tumoral como tal. El nivel sérico de IgG4 fue elevado, $968 \mathrm{mg} / \mathrm{dL}$ (normal $<135 \mathrm{mg} / \mathrm{dL}$ ). El conjunto de los hallazgos descritos, compromiso simultáneo de páncreas y riñones sumado a un valor muy elevado de IgG4, permitió establecer con alta probabilidad el diagnóstico de pancreatitis autoinmune tipo 1 , como parte de enfermedad relacionada a IgG4.

El engrosamiento de los pliegues y de la pared gástrica, observado inicialmente en las imágenes de TAC, fue un hallazgo poco habitual, sin relación alguna con el cuadro clínico. Para estudiar este compromiso, se realizó una endoscopía digestiva alta que mostró, a nivel corporal, un engrosamiento difuso de los pliegues gástricos, los cuales no desaparecieron con la insuflación, observando, además, cierta rigidez de la pared gástrica. El antro impresionó con pared y mucosa normal (Figura $2 \mathrm{C}$ ), concordante con la ausencia de compromiso en las imágenes de TAC (Figura 1 A) y resonancia magnética (RM) (Figura $1 \mathrm{~B})$. En el examen histológico se encontró una infiltración linfoplasmocitaria con presencia de eosinófilos (Figura $3 \mathrm{~A}$ ). En el estudio inmunohistoquímico,
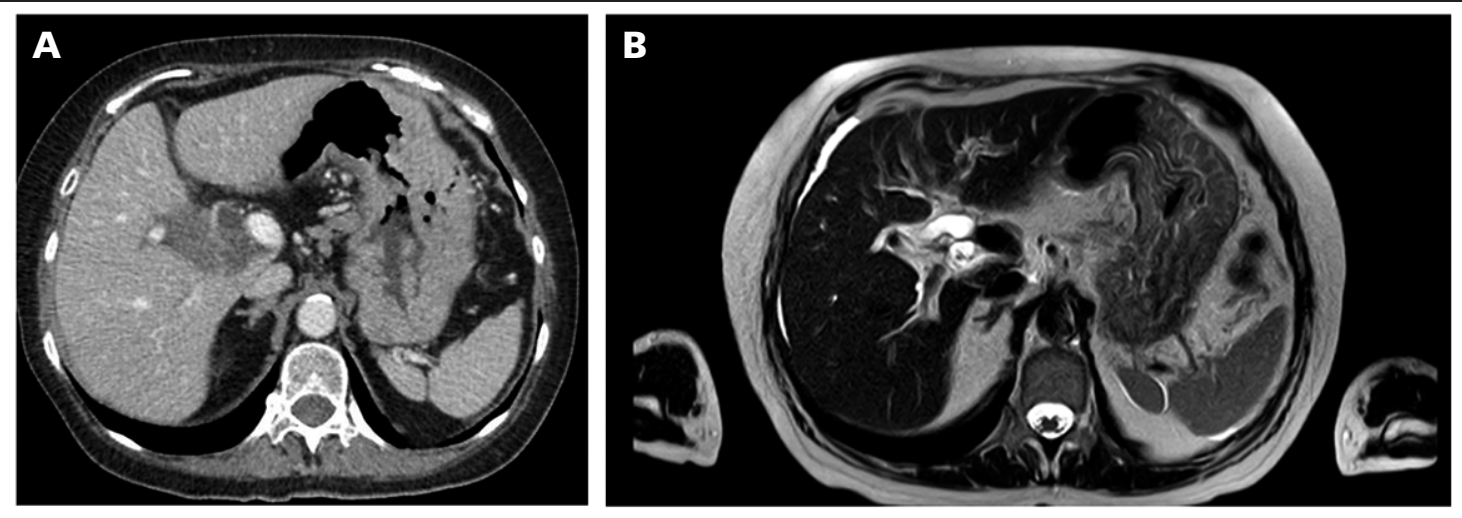

Figura 1. A: Tomografía axial computarizada: en un corte de abdomen se observa pared gástrica muy engrosada, mucosa gástrica edematosa con pliegues extremadamente prominentes. B: Resonancia nuclear magnética: en un corte de abdomen, los pliegues de la mucosa gástrica prominentes, inflamados, ocupan la cavidad del cuerpo gástrico y dejan libre el antro. 

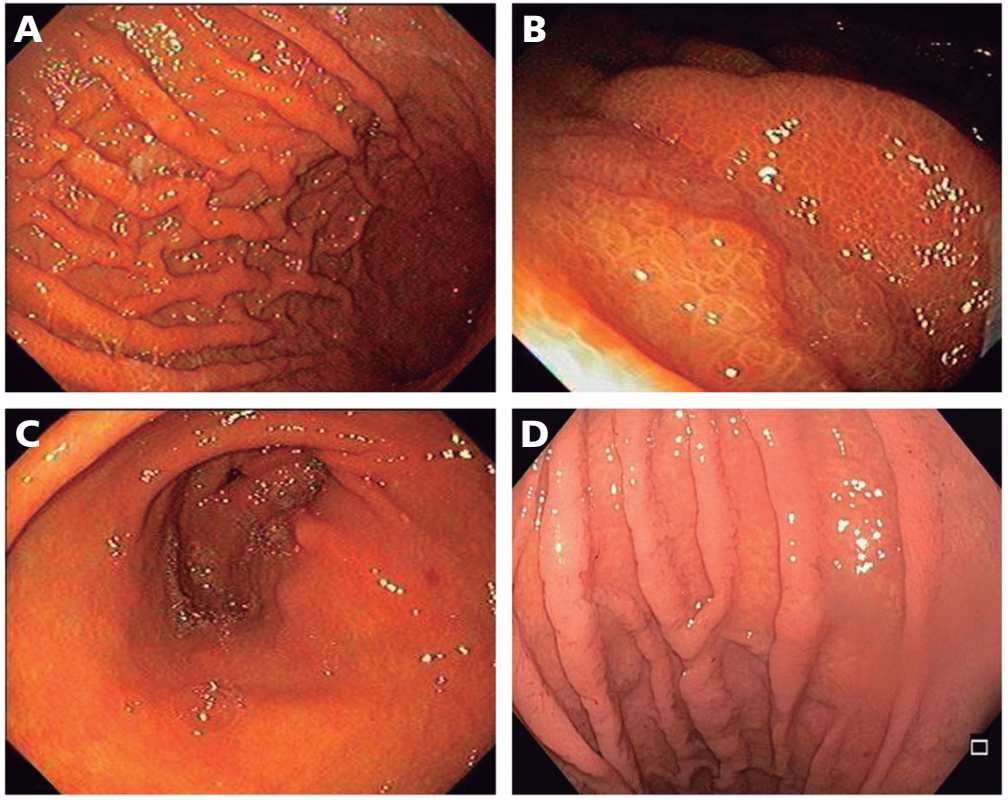

Figura 2. A-B: Vista endoscópica: pliegues gástricos engrosados, hipertróficos, rígidos, que no se aplanan con insuflación de aire. C: Antro gástrico prácticamente normal. D: Vista endoscópica después de 8 meses del inicio de la enfermedad, ya completamente recuperada su pancreatitis autoinmune. Los pliegues gástricos y la mucosa ya son de aspecto normal, no se ve rigidez, se aplanan por insuflación de aire.

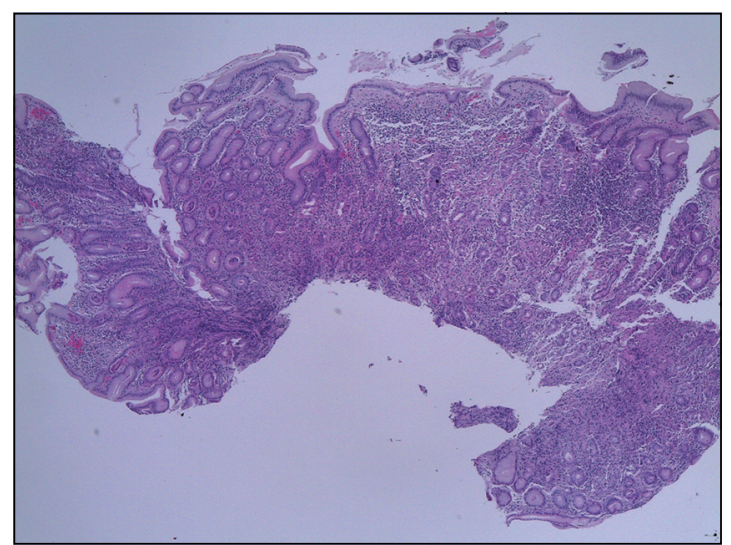

Figura 3 A. Imagen histológica. Microfotografía con aumento $4 x$, teñida con hematoxilia-eosina. Se observa mucosa gástrica corporal con infiltrado inflamatorio crónico denso, con acúmulos linfoides.

25 a 40 plasmocitos por campo fueron positivos a IgG4 (Figura 3 B y C). Se inició tratamiento con corticoides (metilprednisolona $32 \mathrm{mg} /$ día), que se mantuvo durante cuatro semanas y fue reducido $4 \mathrm{mg}$ cada 2 semanas y finalmente suspendido después de 5 meses. La paciente presentó una

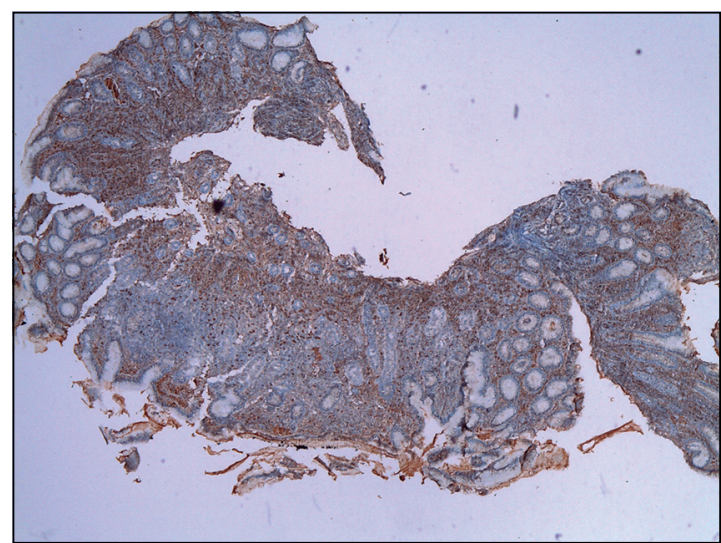

Figura 3 B. Microfotografía con aumento 4x, teñida con inmunohistoquímica con anticuerpos contra lgG4. Nota la reacción positiva densa color café oscuro.

rápida reducción de la ictericia, con normalización completa de las pruebas hepáticas a la sexta semana de tratamiento. A 8 meses del diagnóstico, las imágenes mostraron una recuperación morfológica del páncreas, de la vía biliar y también del estómago (Figura 2 D y 3 D). 


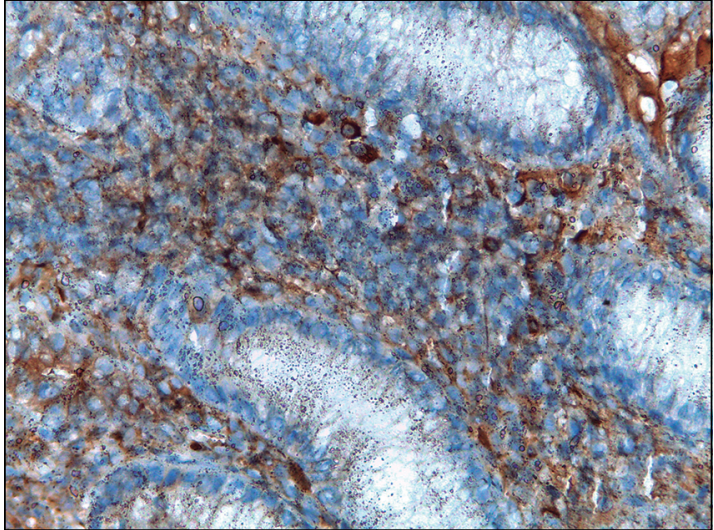

Figura 3 C. Microfotografía con aumento 40x, teñida con inmunohistoquímica con anticuerpos contra lgG4, observándose tinción positiva (café oscuro) en el citoplasma de numerosos plasmocitos (se cuentan entre 25 y 40 por campo).

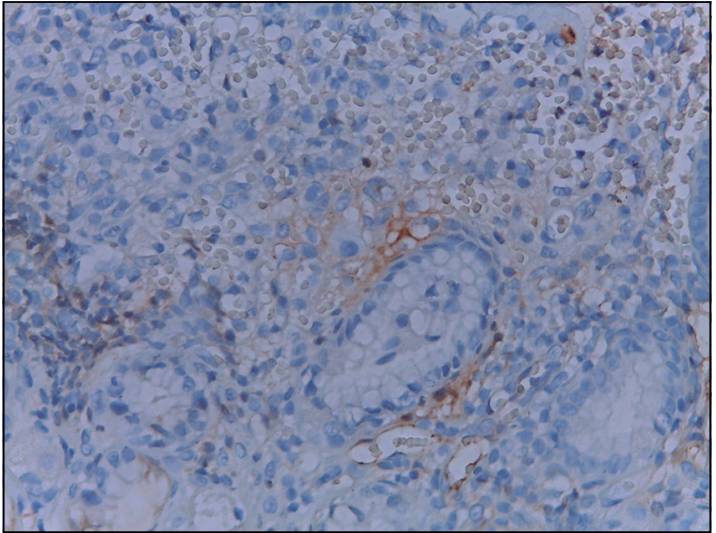

Figura 3 D. Después de tratamiento. Microfotografía con aumento 40x, teñida con inmunohistoquímica con anticuerpos contra lgG4, en la que se observa ausencia de tinción en las células plasmáticas.

\section{Discusión}

La enfermedad por IgG4 es un importante "simulador" en la práctica clínica actual, sus manifestaciones clínicas y morfológicas pueden imitar diferentes patologías, con frecuencia tumorales y otras veces inflamatorias.

Las enfermedades relacionadas a IgG4 han sido ampliamente descritas en múltiples publicaciones, entre ellas también en Chile ${ }^{3-6}$. Desde el punto de vista clínico, el diagnóstico diferencial es de gran importancia: el cuadro clínico y los hallazgos en los estudios de imágenes frecuentemente son compatibles con una neoplasia, llevando al paciente a una intervención quirúrgica o a iniciar un tratamiento quimioterápico. Sin embargo, esta enfermedad es benigna, responde en su inmensa mayoría con recuperación completa al tratamiento con corticoesteroides. El diagnóstico correcto cambia diametralmente el pronóstico, evitando cirugías innecesarias que conllevan riesgo de morbimortalidad y permite un tratamiento conservador de bajo riesgo y con excelentes resultados.

Desafortunamente, el diagnóstico histológico de PAI es muy limitado, siendo el páncreas de difícil acceso y las muestras citológicas obtenidas por punción con aguja fina insuficientes para establecer el diagnóstico definitivo ${ }^{19}$. El alza de IgG4 sérico es el mejor marcador de laboratorio de estas enfermedades. Aunque no es la causa de enfermedad, su nivel aumenta en la mayoría de los casos. Sin embargo, su rendimiento es lejos de ser $100 \%{ }^{20}$, en ninguna publicación sobrepasa a $80 \%$, aun cuando la histología demuestra la infiltración por linfoplasmocitos IgG4 positivos. El reconocimiento de enfermedades asociadas es de gran importancia y ayuda en el diagnóstico clínico. En nuestro caso, el aumento de IgG4 en suero y la asociación con nefritis bilateral, ya fueron suficientes para establecer el diagnóstico clínico correcto, sin embargo, la confirmación histológica fue únicamente posible por la biopsia endoscópica gástrica.

Aunque existen varias publicaciones, reportes de caso ${ }^{8-16}$, el compromiso gástrico es de excepción, siendo nuestro caso el primero descrito en Chile. Cabe destacar que la imagen endoscópica vista era muy similar a la descrita en el síndrome de Ménétrier, con compromiso endoscópico dominante en el cuerpo gástrico, pero a diferencia de este, en nuestra paciente no se observó pérdida de proteína ni signos clínicos sugerentes. En una publicación desde Brasil reportaron una imagen endoscópica similar a la de nuestro paciente, sin embargo, en este caso el paciente presentó un cuadro clínico completo de síndrome de Ménétrier ${ }^{16}$.

En nuestro caso, el examen histológico e inmunohistoquímico de las biopsias gástricas confirmaron la infiltración por plasmocitos, positivos 
a IgG4. La imagen radiológica mostró marcado engrosamiento de la pared gástrica, con distensibilidad disminuida en la endoscopia, confirmando un compromiso más allá de la mucosa, que incluía las capas musculares. Paralelamente con la recuperación completa de la inflamación a nivel del páncreas y los riñones, desaparición de la ictericia y normalización de las pruebas hepáticas, las lesiones gástricas también desaparecieron, lo que fue demostrado por RM y también por endoscopía y biopsia. El compromiso gástrico en la enfermedad relacionada a IgG4 puede ser sintomático, como úlceras en la mayoría de los pacientes ${ }^{11} \mathrm{o}$ síndrome de Ménétrier ${ }^{16}$, puede formar masas ${ }^{9,10,14}$ con sospecha de cáncer o, como se menciona en nuestro caso, puede ser asintomático ${ }^{15}$ y no modificar el cuadro clínico. Aun así, permite la confirmación histológica e inmunohistoquímica de la enfermedad, siendo la biopsia endoscópica de la mucosa gástrica la única muestra fácilmente accesible. En los casos no operados, el compromiso gástrico se recupera con el mismo tratamiento de la enfermedad ${ }^{15}$.

En conclusión: describimos el primer caso de pancreatitis autoinmune tipo 1 , asociado simultáneamente a compromiso gástrico. Aunque la asociación es rara, aconsejamos realizar endoscopia digestiva alta en los pacientes con sospecha de PAI y tomar biopsias para estudio inmunohistoquímico, en particular si se observan algunas alteraciones endoscópicas.

\section{Referencias}

1. Stone JH, Zen Y, Deshpande V. IgG4-related disease. N Engl J Med 2012; 366: 539-51.

2. Kamisawa T, Zen Y, Pillai S, Stone JH. IgG4-related disease. Lancet 2015; 385: 1460-71.

3. Erlij D, Rivera Á, Maya JC, Cuellar C, Correa G, Michalland S, et al. Hemoptisis recurrente asociada a falla renal y hematuria: otra de las mil caras de la enfermedad relacionada a IgG4. Rev Med Chile 2017; 145: 131-4.

4. Erlij D, Ramos D, Montaña J, Kusnir P, Correa G, Neira O. Enfermedad relacionada a IgG4, el nuevo "gran simulador": caso clínico. Rev Med Chile 2014; 142: 646-50.

5. Vega J, González J, Goecke H, Carrasco A, Santamarina M. Fibrosis retroperitoneal idiopática metacrónica- mente asociada a seudotumor de la cabeza de páncreas. Terapia exitosa con corticoides y colchicina. Nefro Plus 2011; 4: 39-44.

6. Berger Z, Mancilla C. Enfermedad relacionada a IgG4: Manifestaciones extrapancreáticas en pancreatitis autoinmune. Rev Med Chile 2014; 142: 1350-1, Carta al Editor.

7. Berger Z, Jiménez A, Mancilla C, Araneda G, Sedano R. Autoimmune Pancreatitis Rarely Progresses to Advanced Chronic Pancreatitis - Experiences from Chile. JOP. J Pancreas (Online) 2018; 19: 223-7.

8. Inoue $\mathrm{D}$, Yoneda $\mathrm{N}$, Yoshida $\mathrm{K}$, Nuka H, Kinoshita J, Fushid S, et al. Imaging and pathological features of gastric lesion of immunoglobulin G4-related disease: A case report and review of the recent literature. Mod Rheumatol 2016; 21: 1-5.

9. Woo CH, Yook JH, Kim Y, Kim J. IgG4-Related Disease Presented as a Mural Mass in the Stomach. J Pathol Transl Med 2016; 50: 67-70.

10. Inoue K, Okubo T, Kato T, Shimamura K, Sugita T, Kubota M, et al. IgG4-related stomach muscle lesion with a renal pseudotumor and multiple renal rim-like lesions: A rare manifestation of IgG4-related disease. Mod Rheumatol 2018; 28: 188-92.

11. Shinji A, Sano K, Hamano H, Unno H, Fukushima M, Nakamura N, et al. Autoimmune pancreatitis is closely associated with gastric ulcer presenting with abundant IgG4-bearing plasma cell infiltration. Gastrointest Endosc 2004; 59: 506-11.

12. Baez JC, Hamilton MJ, Bellizzi A, Mortele KJ. Gastric involvement in autoimmune pancreatitis: MDCT and histopathologic features. JOP 2010; 11: 610-3.

13. Kawano H, Ishii A, Kimura T, Takahashi T, Hironaka H, Kawano M, et al. IgG4-related disease manifesting the gastric wall thickening. Pathol Int 2016; 66: 23-8.

14. Bulanov D, Arabadzhieva E, Bonev S, Yonkov A, Kyoseva $\mathrm{D}$, Dikov T, et al. A rare case of IgG4-related disease: a gastric mass, associated with regional lymphadenopathy. BMC Surgery 2016; 16: 37 (5 pages).

15. Koizumi S, Kamisawa T, Kuruma S, Tabata T, Chiba K, Iwasaki S, et al. Immunoglobulin G4-related gastrointestinal diseases, are they immunoglobulin G4-related diseases? World J Gastroenterol 2013; 19: 5769-74.

16. Fonseca Chebli JM, Andrade Chebli L, da Rocha Ribeiro TC, Duarte Gaburri P. Severe hypoproteinemia as a harbinger of Ménétrier's disease in autoimmune pancreatitis. Rev Assoc Med Bras 2017; 63: 215-8.

17. Kim MH, Moon SH, Kamisawa T. Major Duodenal Papilla in Autoimmune Pancreatitis. Dig Surg 2010; 27: 110-4.

18. Dacha S, Chawla S, Lee JE, Keilin SA, Cai Q, Willingham 
FD. Endoscopic retrograde cholangiopancreatography with ampullary biopsy vs ERCP alone: a matched-pairs controlled evaluation of outcomes and complications. Gastroenterol Rep 2017; 5: 277-81.

19. Morishima T, Kawashima H, Ohno E, Yamamura T, Funasaka K, Nakamura M, et al. Prospective multicenter study on the usefulness of EUS-guided FNA biopsy for the diagnosis of autoimmune pancreatitis. Gastrointest Endosc 2016; 84:241-8.

20. Yu KH, Chan TM, Tsai PH, Cheng CH, Chang PY. Diagnostic performance of serum IgG4 levels in patients with IgG4-related disease. Medicine 2015; 94: e1707. 